\title{
Meaning as a Product of Play between 'Privileged' and 'Marginal': A Deconstructive Analysis of $A$ Case of Exploding Mangoes by Muhammad Hanif
}

\author{
Malik Haroon Afzal (Corresponding author) \\ School of Humanities, University Sains Malaysia, Malaysia \\ Email: mharoon176@gmail.com \\ Mohamad Rashidi Mohd Pakri \\ School of Humanities, University Sains Malaysia, Malaysia \\ Nurul Farhana Low Abdullah \\ School of Humanities, University Sains Malaysia, Malaysia
}

Received: $16 / 08 / 2020$

Accepted: 05/10/2020

Published: 01/11/2020

Volume: 1 Issue: 2

How to cite this paper: Afzal, M. H., Pakri, M. R. M., \& Abdullah, N., F., L. (2020). Meaning as a Product of Play between Privileged and Marginal: A Deconstructive Analysis of A Case of Exploding Mangoes by Muhammad Hanif. Journal of Practical Studies in Education, 1(2), $1-8$

DOI: https://doi.org/10.46809/jpse.v1i2.12

Copyright (C 2020 by author(s) and Global Talent Academy Ltd. This work is licensed under the Creative Commons Attribution International License (CC BY 4.0).

http://creativecommons.org/licenses/by/4.0/

\section{(c) (1)}

\begin{abstract}
The buoyant shift from form and structure to the fluid constructs of meaning turned discernible in Jacques Derrida's Deconstruction. Meaning or reality that had so long been enjoying a fixed and definite status was worn out with the advent of the theory of deconstruction. The turnaround of what was considered real or true became subjacent while challenging all the existing binaries that had been hegemonizing human comprehension of the world (Derrida, 1997). Relying on the theory of deconstruction by Jacques Derrida, the study examines the shift from form and structure to the text itself regarding its privileged and marginal aspects of meaning with particular reference to the novel A Case of Exploding Mangoes. The study suggests that the interplay between privileged and marginal aspects of meaning can constructs multiple meanings and interpretations of a single text. It has further been added that the nature of the theory of deconstruction-change in the fixed status of meaning/reality - at the same time, is a representation of the indefinite nature of modern man who has experienced a bumpy ride of social and religious values resulted due to the political, industrial, economic and technological revolutions. The paper finds that the fluidity of meaning that is the sole characteristic of the theory of deconstruction traverses the contemporary Pakistani fiction in its dealing of the sensitive matters such as religious extremism and dictatorship etc., and Muhammad Hanif's selected novel is the perfect example of it.
\end{abstract}

Keywords: Deconstruction, Post-Modernism, Privileged/Marginal Aspects, Meaning 


\section{Introduction}

Muhammad Hanif is a Pakistani Novelist and Journalist who became famous for his novel A Case of Exploding Mangoes. The novel was published in 2008 and won the Best First Book Award in 2009 in the Commonwealth Book Prize. It emplots a comic description of cynical characters webbing different conspiracy theories in the political milieu during one of the most significant military regimes in the history of Pakistan -that ended with the assassination of Gen. Zia, the then Chief Martial Law Administrator. The novel is famous for its mixture of suspense and comedy. The present research examines it in the backdrop of Derridian 'signifier' and 'transcendental signified', or 'marginal and unprivileged signified', that implies that there is 'no outside text' (1997, p. 158-159). Aziz Yousif Al-Muttalibi (2018) quotes Curie and says, "Deconstruction does not envisage text, any text, to be distinct separate whole but as having irreconcilable and contradictory aporia of text" (p. 145).

A theoretical framework has been developed with the help of Derrida's three essays: Structure, Sign and Play and the Discourse of Human Sciences; The Father of Logos from Plato's Pharmacy, and Differance. The framework utilizes different Derridean constructs like Structure, Sign, Logos and Differance and provides a reading model for the deconstruction of texts on one hand, and its application in the novel A Case of Exploding Mangoes by Muhammad Hanif on the other. The initial review of the existing literature unfolds that deconstruction as a critical approach and the literary text have a strong relationship - in terms of the construction of meaning - to the extent that "The critical text and the literary text are each parasite and host for the other, each feeding on the other and feeding it, destroying and being destroyed by it" (Miller, 1993, p. 249). Moreover, deconstruction's heavy emphasis on what is 'absent' has made the process of meaning extraction more complex by opening a new way to multiple meanings and interpretations. Seldon (1989) sees this process of deconstruction as:

The deconstruction begins by disclosing the hierarchically ordered, metaphysical substratum of a specific piece of discourse. The pairs of terms (soul/body, being/non-being, good/bad, content/form, truth/lies, essential/inessential, speech/writing, masculine/feminine, and so on) are assumed to form a hierarchy of value or truth which allows the writer to exclude from the field of discourse those connotations or meanings which do not accord with the privileged terms. 'Body' is excluded as transitory and inessential; 'form' is superficial and variable; 'feminine' is a defective or weaker form of 'masculine'. The deconstructor proceeds by reversing the hierarchy, not perversely but by discerning a chink in the discourse which allows this reversal. Finally, the newly- asserted hierarchy is itself displaced and is not allowed to install a new 'truth' or structural fixity. The rule of indeterminacy prevails. While structuralists had treated binary oppositions ... as stable terms in a formal structure, Derrida sees them as orgnised in unstable disequilibrium. (p. 89)

Viewing the plot of the selected novel with the lens of above-mentioned aspect of deconstruction-indeterminacy of truth - it becomes clear that the novel enables the reader to constitute multiple assumption and interpretations even about a single incident that ultimately leads to 'multifarious realities' and 'confusions'. The present paper attempts to deconstruct these confusions by applying this post-modernist approach on the selected text in order to establish that this confusion is one of the chief most characteristics of post-modernism that has enabled us to examine and challenge the already fixed power structures. The present research attempts to explore the way Derrida's 'absent' or 'unprivileged' is supplementing the intertextual and contextual meaning of the selected novel as well as it explores the way the novel challenges the existing glamourous and heroic image of army in Pakistan. Therefore, the present article strives to find the way the indefinite status of meaning leads to the greater confusion regarding different political events in our selected text that ultimately challenges the fixed notion of reality within that particular context.

\section{Theoretical Framework: Structure, Transcendental Signified and Free-Play}

According to Derrida, in any structure 'event' holds an important position or vice versa. Even if structure completes the meaning of an event or reduces it, Derrida takes it as something that "will have the exterior form of a rupture or redoubling" (1967). The 'structure' and 'event' together take the position as 'thesis' and 'antithesis' in Hegelian terms and their 'synthesis' produces what we call 'meaning'. From this it can be deduced that the structure needs the event or the context to be structured. The 'event' is not dependent on its structure. The very presence of the 'event' brings along the structure within itself. In Structure Sign and the Play of Human Discourse Derrida says that the origin of structure is as old as the origin of epistemology, the way epistemology tried to get hold of all the knowledge, structure also tried to get hold of everything and gain "a fixed origin" (1978, p. 351-352). The structure, therefore, gets the privileged position in its struggle with the event.

But later, he goes further and states that the problem with this uniform traditional structure or the centralized structure is that it limits the free play. Ideally, the centre of the structure allows the free-play within the form of that structure but the very organizing principle of the structure interdicts all the possible permutations within that structure. Derrida confirms this demerit of the 'fixed structure' as: "the center also closes off the freeplay it opens up and makes possible" (1978, p.352). He questions the very idea of center by highlighting the limitation of the center because center does not and cannot represent the whole spectrum. Thus, the margins will look for their center somewhere else or naturally their center will go somewhere else: 
This is why classical thought concerning structure could say that the center is, paradoxically, within the structure and outside it. The center is at the center of the totality, and yet, since the center does not belong to the totality (is not part of the totality), the totality has its center elsewhere. (Derrida 1978, p.352)

Hence, the idea of center has been challenged and limited in its scope because center is a fraction and a fraction cannot stand for the whole. Now the question that why this center has been given so much importance? The simple answer is that there has been so much emphasis on the visible or the present. Things have been given importance based on their presence, and this very notion has been criticized in the critique of Deconstruction:

From the basis of what we therefore call the center (and which, because it can be either inside or outside, is as readily called the origin as the end, as readily arche as telos), the repetitions, the substitutions, the transformations, and the permutations are always taken from a history of meaning [sens]- that is, a history, period - whose origin may always be revealed or whose end may always be anticipated in the form of presence. (Derrida 1978, p.352-53)

Center formation is an old human practice and it is so frequent that it has taken the form of addiction. We are so addicted to the centers that we often replace centers with other centers. Now the idea of center can be replaced by 'presence' which has been bestowed with a privileged stance. These presences include essence, existence, substance, subject, transcendentality, consciousness, or conscience, God, Man, and so forth. For human beings these constructs which probably have been constructed by humans themselves have been the privileged centers, because they have been given so much importance that they have become real. The 'presence' which is the construction of 'human thought' and that powerful 'human thought', which has constructed the 'real', has been marginalized. Derrida denounces that privileged construction a 'surrogate' and then declares that this surrogate cannot make the margin or the process of its making cannot be reversible:

Henceforth, it became necessary to think both the law which somehow governed the desire for a center in the constitution of structure, and the process of signification which orders the displacements and substitutions for this law of central presence-but a central presence which has never been itself, has always already been exiled from itself into its own substitute. The substitute does not substitute itself for anything which has somehow existed before it. (Derrida 1978, p.353)

Quite similar to the above discussion about 'center/structure' and 'human thought/free play' the structure of the language and its meaning is supplemented by the very 'marginal thought' or the 'transcendental signified' which is completing the language. Without that 'thought' or 'transcendental signified' the structure of language is limited and this limited structure is no structure at all because its completion is lying outside it, in the context or in the individual thought of the perceiver. It's not the structure which is completing the discourse but the once ignored 'transcendental signified', the absence of which "extends the domain and the play of signification infinitely" (Derrida, 1978, p. 354). This paper highlights the 'freeplay' of meaning in the selected novel by examining the working of these two Derridian constructs: Structure (signifier) and transcendental signified.

\section{Sign and Free-Play}

Derrida calls center as metaphysics of presence and asserts that without the concept of sign the attack on the metaphysics of presence would have never been possible. According to Derrida signifier's presence is also metaphysical because it needs a transcendental signified for its completion or for what we call the process of signification (1978). The gap between intelligible and sensible cannot be reduced. Derrida criticizes Claude Levi-Strauss for putting that claim in his essay The Raw and The Cooked when he asserts that he has placed himself at the level of sign between the intelligible and the sensible. He holds the belief that for the very existence of sign, this opposition between signifier and signified is a must. However, according to the structuralist approach, sign is the product of differences. This difference is the difference between different signs. And this difference further leads to the arbitrariness of the language. Now there is another question that how can we deconstruct the sign? According to Derrida, we can deconstruct a sign by erasing the difference between the signifier and signified, and there are two ways to erase it and these are:

For there are two heterogenous ways of erasing the difference between the signifier and the signified: one, the classic way, consists in reducing or deriving the signifier, that is to say, ultimately in submitting the sign to thought; the other, the one we are using here against the first one, consists in putting into question the system in which the preceding reduction functioned: first and foremost, the opposition between the sensible and the intelligible. For the paradox is that the metaphysical reduction of the sign needed the opposition it was reducing. The opposition is systematic with the reduction. (Derrida 1978, p.355)

These two ways directly or indirectly connect to the language and the system. The deconstruction of sign involves the deconstruction of language at one side and the deconstruction of the system on another i-e the system in which that language has been constructed. The status of discourse is the product of the respective cultural heritage which cannot be further deconstructed without the deconstruction of its language structures:

The quality and the fecundity of a discourse are perhaps measured by the critical rigor with which this relationship to the history of metaphysics and to inherited concepts is thought. Here it is a question of a critical relationship to the language of the human sciences and a question of a critical responsibility of the discourse. It is a question of putting expressly and systematically the problem of the status of a discourse which borrows 
from a heritage the resources necessary for the deconstruction of that heritage itself. A problem of economy and strategy. (Derrida 1978, p.356-357)

In the light of above discussion, it can be concluded that the relationship between sign and 'the inherited concepts of thought' plays a vital role in the deconstruction of process. In other words, the 'system' or 'the cultural heritage' plays an important role in the construction of meaning; the opposition between 'sensible' and 'intelligible' which is akin to the 'metaphysical reduction' needed for the deconstruction of 'sign'. This article sees the meaning of the text as a product of that 'metaphysical reduction' and the opposition between the 'sensible' and the 'intelligible'.

\section{Logos and Différance}

The dominance of 'speech' over 'writing' is something historical. Traditionally and culturally it is thought that the first form of language is the spoken one. This is one dimension but there is another aspect too, which has been highlighted by Derrida in his essay The Father of Logos from Plato's Pharmacy that speech validates the authority or authenticity of writing. He tells a tale of Egyptian god Theuth who needed the approval of another god Thamus who was higher in rank but didn't know how to write. The speech of Thamus had to validate the thesis of Theuth. Derrida goes on and asserts that it is not that speech but the origin of that speech which is father, god-father:

Not that logos is the father, either. But the origin of logos is its father. One could say anachronously that the "speaking subject" is the father of his speech. And one would quickly realize that this is no metaphor, at least not in the sense of any common, conventional effect of rhetoric. Logos is a son, then, a son that would be destroyed in his very presence without the present attendance of his father. His father who answers. His father who speaks for him and answers for him. Without his father, he would be nothing but, in fact, writing. At least that is what is said by the one who says: it is the father's thesis. (Derrida 1972, p.77)

Nevertheless, if someone has to deconstruct the speech he has to deconstruct the status of the speaker by examining the 'origin of logos'. According to Derrida, "Logos is thus a resource. One must turn to it" (1972, p. 84). By doing so, he attaches the 'exteriority' of the signifier to that unprivileged 'transcendental signified' and awards it a privileged status. Hence the 'exteriority' finds its way from thought to status and from status to the context. This paper turns to 'logos' as a resource to analyze multiple interpretations the selected text gives vent to. On the other hand, 'Differeance' is a term that has been coined by Derrida for the denial or reversal of everything that has ever existed before. This radical construction changed the thinking patterns of all the literary critics and became a hallmark in western literary tradition. In case of language, it is an attribute "by which meaning is generated because of a word's difference from other words in a signifying system, and at the same time, meaning is inevitably and infinitely deferred or postponed, is constantly under erasure and can be glimpsed only through "aporias" or deadlocks in understanding" (Mambrol, 2016). That 'deadlock' or 'aporia', which is "an irresolvable internal contradiction or logical disjunction in a text, argument, or theory" further constructs 'meaning' and defers it to another one till infinity. This paper strives to analyse these 'aporias' within the text of selected novel by highlighting its effect on meaning and different interpretations. However, Derrida elaborates this concept in an interview that was translated by David B. Alison, as:

The verb "to differ" [differer] seems to differ from itself. On the one hand, it indicates difference as distinction, inequality, or discernibility; on the other, it expresses the interposition of delay, the interval of a spacing and temporalizing that puts off until "later" what is presently denied, the possible that is presently impossible. Sometimes the different and sometimes the deferred correspond [in French] to the verb "to differ." This conelation, however, is not simply one between act and object, cause and effect, or primordial and derived. (Richter, 1989, p. 932)

As discussed before, this theory of deconstruction has actually built up an intersection which is going against the fixities and connecting so many critical disciplines together. Derrida himself declares that this "Differance is neither a word nor a concept. In it, however, we shall see the juncture - rather than the summation - of what has been most decisively inscribed in the thought of what is conveniently called our "epoch"' (Richter, 1989, p. 933). This difference between 'difference' and 'differance' is only graphic. He questions the authority of spoken language over written one. He takes the spoken language down from a privileged position and maintains that even the spoken language sometimes needs written expression for its complete understanding and meaningfulness, and that the written expression is the complement of spoken one because it completes its meaning:

Now, in point of fact, it happens that this graphic difference (the a instead of the e), this marked difference between two apparently vocalic notations, between vowels, remains purely graphic: it is written or read, but it is not heard. It cannot be heard, and we shall see in what respects it is also beyond the order of understanding. (p. 934)

According to him, there exists no phonetic writing and the phones are being taught and communicated by means of graphic signs that have long been marginalized. 'Differance' as a term has far reaching implications: the above discussion has shown its shift from 'aporias within the language' to the 'deadlocks in the nature of reality' (Derrida, 1997). However, the current article focuses only on the former construct of 'diffarence' in the selected novel to see how these aporias of the "irresolvable internal contradiction or logical disjunction in a text" (ibid) help in the construction of multiple interpretations and meanings. 


\section{Textual Analysis: Deconstruction at Textual Level}

Throughout the course of the theoretical framework, it can be seen that deconstruction revolves around two poles i-e the presence and the absence; signifier and transcendental signified; sensible and intelligible; exteriority of sign, and aporias within the language or reality. Traditionally and historically 'presence' has enjoyed the supreme status holding the privileged position whereas 'absence' has suffered as an insignificant pole. The present research maintains that this presence is all about the surface structures, or the things those are present. In the case of discourse or text, it is the told, written and described material/information - privileged - which is entirely and solely dependent on the absent, i-e., what has not been toldmarginal — which is the reader or listener's assumption, background or historical knowledge about that particular context and situation. In this way Derrida helps us to maintain that 'meaning is a product of play between privileged and the marginal' because meaning or interpretation is not generated by the text but by the time, history, and context.

However, the application of the theory of Deconstruction on the novel A Case of Exploding Mangoes suggests that the novel in hand is like a cobweb having multiple ends but no conclusion. The mysteries those have been constructed in the beginning stay mysteries till the concluding chapter. The story revolves around the fictional character of General Zia, a fictional representation of former Pakistani Chief Martial Law Administrator who was assassinated in a plane crash. The incident left the people curious all over the world that how that incident happened? What were the principle causes behind that incident? The study, by contextualizing the novel within the domain of deconstruction, propounds that the curiosity regarding this incident and the historical knowledge about it became the sole reason of the success of this novel. Moreover, the writer has knitted a web of different conspiracies regarding the murder of Gen Zia which at one point seem to be true and at other time false. The present research claims that these revolving conspiracies are a product of all the textual 'aporias'.

The paper shows the 'power play between the privileged and the marginal' by stating that throughout the novel reader's perception of meaning is different and that difference is caused by his own understanding of the context and the background knowledge. Most of the time that meaning is different from what is stated. It is because of the differance between one 'transcendental signified' and the other, that every time creates conflict and 'deffer' the meaning because of different hierarchal relationships. For example, in the very start of this novel, when Under Officer Ali Shigri presents his statement and claims that he doesn't know that why his friend Obaid has gone AWOL (Absent without Official Leave) (Hanif, 2008, p.1). But when he is asked that why he has marked his friend's attendance in the morning parade, he keeps mum. The incident creates a conflict in the mind of the reader which ends up in a play between different thoughts and signifiers; and stimulates a suspicion in the mind of the reader that Ali Shigri is hiding something. The reader gets his suspicion confirmed in the end of the novel that not only they had discussions about the conspiracy but also he knew where probably Obaid would go. The assumption which we consider a mere thought and ignore or marginalize is actually that 'transcendental signified' which contributes to the meaning process. Shigri's answer, although, doesn't literally and actually state that he knows the truth, but it does affirm an affiliation between two friends. If we see it with deconstructionist perspective, the text that is present, hence privileged, affirms the unawareness of Ali Shigri from the incident but the reader's 'thought' or 'assumption' that is marginal gives the text the true meaning that he has a clue about the incident through a process of defferance. At this point, reader's assumption plays a role of Deridda's 'transcendental signified' which actually accords the meaning to the text. In addition to this, the very suspicion or the interpretation about Shigri's character proves right when both of them are set free by the new General of ISI, Gen Baig:

You did it to save my ass? You just thought you would take off in a stolen plane, head for the Army House and they would all simply sit and monitor your progress? Do you even have any idea how many ack-ack guns there are around that bloody place? They probably shoot down stray crows over there. (Hanif, 2008, p.127)

The very dialogue of Ali Shigri while scolding Obaid shows that both of them had had some discussion about the assassination of Gen Zia which he could have revealed to the investigator at first place. This example from the texts not only confirms but validates Derrida's 'sensible and the intelligible' and binary oppositions. On the other hand, Obaid was also aware of Ali's plan to take revenge of his father's murder from Gen Zia to which Obaid tried to avoid:

You are still not listening to me, Shigri. I am not a kamikaze. You have all these expectations of your friends.

You think I was going to do it for you? Sorry, I was just providing a diversion. I used your call sign, so that you couldn't carry out your silly plan. A sword, for God's sake. A sword? (Hanif 2008, p.127)

It's not the case that the reader came to know in the end of the novel the fact that Shigri and Obaid were more than a close association. Reader gets to know it even at the very beginning of the novel when he deconstructs Obaid and Shigri's relationship as well as the perception of people about them. The knowledge of the reader can be termed as assumption, guess or any speculation but this article claims that it's not reader's assumption but it's that 'transcendental signified' which makes the existence of 'meaning' or 'sensible' possible. Similarly, this intention of Ali Shigri that he wanted to kill Gen Zia to avenge his father's murder becomes evident from the start on his course of giving description about his father. Reader gets to know his intentions even before narrator's narration. Even before the 'text' is presented, the meaning is conveyed. And this phenomenon has been realized due to Derridian 'thought' that has so long been marginalized, but in reality which is the actual complement of the meaning:

Yes, that nine-inch bronze man with pistol is mine. Best Short Range Shooting Shigri Memorial Trophy, named after Colonel Quli Shigri, won by Under Officer Ali Shigri. [...] I don't want to think right now about Colonel Shigri or the ceiling fan or the bed sheet that connected them. Thinking about Dad and the ceiling fan and the 
bed sheet always makes me either very angry or very sad. Not the right place for either of these emotions. (Hanif 2008, p.11)

Moreover, Ali Shigri's belief that Major Kiyani had killed his father and it was a murder, not a suicide is again an inference out of the text or narrator's narration. The only thing that has been shared by the narrator is the description of Late Col. Shigri's death and Major Kiayyani's presence on the funeral and his instructions to Ali Shigri to not to pursue autopsy. The close reading of the text enables the reader to bring in his thoughts and hierarchical knowledge to deconstruct the plot and give it a meaning:

Or, as I know from personal experience, he appears quietly at funerals after accidental deaths and unexplained suicides and wraps things up with a neat little statement, takes care of any loose ends, saves you the agony of autopsies and the foreign press speculating about decorated colonels swinging from ceiling fans. He is a man who runs the world with a packet of Dunhills, a gold lighter and an unregistered car. (Hanif 2008, p.35)

There are numerous other examples in the text where meaning has been constructed in the same way. Although, we have reached to the conclusion that the meaning is the product of play between privileged and the marginal; and binary oppositions play an important role in the construction of reality, it is being extended that because the selected novel leaves the meaning and interpretation on the reader, it has made the plot more complex and unconcluded which is the foremost characteristic of post-modernism. Pulido quotes Hall (2001), "Whereas structuralism makes the meaning of a text definitive, deconstruction enables the readers to come up with their own interpretation that may be justified through the use of the organizing principles of language and signification" (2011, p. 80). It is suggested in this paper that these individual interpretations are correct most of the times because of these 'organizing principles of language and significations' which makes their construction possible. For example, the sexual relationship between Ali Shigri and Baby' O (Obaid): Ali denounces any kind of physical relationship even at the very beginning of the novel but the reader becomes aware of the fact, that they actually had developed physical relation, with the help of so many other signifiers. For example, at one place Obaid's character appears as sensitive and girlish, and on the other side Ali Shigri plays a strong and manly character. Moreover, their personal dealings and frankness too becomes self-evident of a same-sex relationship:

Obaid came and stood in front of me, flipped his eyepatch and extended his tongue, offering me the halfchewed cardamom shell: a green fly on the red velvety tip of his tongue. I took it and put it in my mouth, savouring its sweet smell. The bitter seeds had already been eaten by him. (Hanif 2008, p. 69)

The play between privileged and marginal and the way absence complements presence and accords meaning to it can be seen clearly in the relationship of Shigri and Obaid. For example, the fact that both had physical relationship was denied throughout the novel by characters' actual assurances in the form of text (Presences), but the reader knows the otherwise situation by imagining their personality traits, and their mutual bond (Absence; Transcendental signified). Derrida's critique that the absence/unprivileged/transcendental signified complements the present and accords meaning to it, becomes clear in the aforementioned example where the reader is not depending entirely on the text but on his background cultural and historical knowledge for the extraction of meaning. The study adds that the 'absence' is a standpoint to see beyond what is said, because it puts the reader in quest for meaning; lights up the fire so that he starts searching for meaning. Unable to find meaning within the text, and to quench his thirst for meaning, he moves beyond the text and it is the point where he links with Derridian 'transcendental signified' or 'the intelligible'. It can be clearly seen that in the concluding chapters Ali Shigri's confessional statement soothes all the assumptions of the reader:

There was more surprise for me as he wriggled out of his pants and took my hand to his cock. I found myself tracing a curve, not just a slight curve, but the semicircle of a new moon. His cock was bent like a bow and his erection arched towards his navel. He sighed and lay down beside me. His eyes were shut and a gentle smile was spreading around his lips, a smile so serene, so full yet gentle, that he seemed to have retreated into his world where the wind whispered in his face and the ocean beneath him was still. (Hanif 2008, p. 90)

Even about the character of Gen Beg, text has presented itself for a complement of thought to complete and give it the meaning that he was the conspirator even at the very first appearance through the dialogue of Ali Shigri: Our saviour wears Ray-Bans and doesn't take them off as we are hauled before him. Major Kiyani and his reformed hoodlums are nowhere in sight. (Hanif, 2008). Ali Shigri wanted to kill Gen Zia, he too wanted to kill him. Narrator's description of Gen Beg as a 'saviour' affirms that both of them were sailing in the same boat. And it was proved in the end when he called South Asia Desk and pleaded that the US Ambassador shouldn't join the mango part on Pak One:

The chief communication officer in Langley throws his hands up in the air and reports that the ambassador is probably having a very long siesta. "Pak One has got clearance to taxi. It is taking off within minutes," reports the communication satellite picking up the air traffic control's calls from the garrison. The duty analyst at the South Asia Desk looks at all the calls logged in his register, starting with the first call made by a general with the unlikely name of Beg who had pleaded that the US Ambassador shouldn't join the mango party on Pak One and decides that there is no need to pursue the matter any further. (Hanif 2008, p. 148)

Gen. Baig's reservation that "US ambassador shouldn't join the mango party on party" allows the transcendental signified to construct the reality that he too was involved in the assassination of Gen. Zia. However, viewing holistically, the novel imagines many characters as the culprits behind the explosion of Pak One, but doesn't solidify its imagination by leaving it on the reader to decode and deconstruct the mystery involved in the explosion. 


\section{Deconstruction at Historical Level}

As it has been mentioned earlier that this fiction is a product of a real-life incident and the reader feels himself more linked with the story due to the historical linkage which the writer becomes successful in developing. As Derrida implies that the knowledge of history also contributes in the development of truth. Just like education complements nature, historical knowledge too complements the truth and the meaning. Post-Modernists say that the truth or meaning is not fixed, this is because it is dependent on the knowledge of history and culture. However, according to Derrida, the meaning or interpretation attached to a particular social or political incident can be achieved by demystifying or deconstructing it. The present novel provides an alternative history of war between Soviet Union and Afghan Mujahideen, or Soviet Union and America. The ultimate quest for power - both nationally and internationally - and its consequences and the politics involved in that has been one of the dominant themes of this novel. Therefore, the article suggests that the reader's knowledge of the history over here helps him to draw meaning out of the text. General Zia ul Haq, the Chief Marshal Law Administrator of Pakistan remained in power for eleven years until his death in a plane crash. His government has been critsized by so many because of his policies and Islamic reforms. So much so, he ruled for eleven years which is quite a long duration and it was quite natural for him to be surrounded by the conspirators. Similalry, in the novel when the reader comes across the dialogue of General Akhtar Abdur Rehman who is the Chief of ISI (Inter-Services Intelligence), he automatically takes him as the one who is behind the plot of General Zia's murder:

And my friend," Bill mimed General Zia's moustache with the thumb and forefinger of his right hand, "is he really having these visions? [...] General Akhtar smiled a coy smile, puffed out his chest and said in a very concerned tone. "Eleven years is a long time. He's a bit tired. (Hanif 2008, p.39)

This is the very first meeting of the reader with Gen Akhtar's character. It is the historical knowledge of the reader which has enabled him to deconstruct the given dialogue. Similarly, the American Ambassador Arnold Raphel, in the last chapter when boards $\mathrm{C} 130$ on the persuasion of Gen Zia, makes a very honest comment about their tanks by declaring them 'useless': "No, Mr President, they are as useless as tits on a boar." (Hanif 2008, p.151) It seems a comment of a person who knows that he is going to die soon because honesty and truth are associated with the death bed normally. The historical knowledge that CIA was behind the assassination of Gen Zia actually takes the reader to the meaning that Arnold Raphel knew that CIA was involved, and he didn't leave the plane because he was carrying out the official orders.

\section{Deconstruction at Cultural Level}

Differences in meaning are akin to the cultural differences. The most important thing is the role of myths in any culture. The structuralist, Claude Levis Strauss in his essay The Raw and The Cooked emphasizes upon the structure of the myth as a tool to unveil truth. Just like 'morpheme', he declared 'mytheme' as the minimal unit of myth (Richter, 1989, p. 859). Jacques Derrida, in his essay Structure, Sign and Play and the Discourse of Human Sciences talks about the deconstruction of that myth. How this myth helps to construct meaning? Just like thought and historical knowledge, the knowledge of culture also contributes in the process of meaning formation.

In the novel, A Case of Exploding Mangoes, just like 'sign' and 'history', cultural formations and myths are also playing an important role in the construction of its various themes and lead to different interpretations. There are various myths in our Pakistani culture like 'being cursed' will bring you bad luck and continuous presence of crows can also inflict trouble upon you. The presence of these myths in the selected novel has also equipped its reader to establish the meaning. While peeping into the text to figure out the possible causes of the death of Gen Zia, the reader also considers the curse of blind Zainab as a possible reason behind Zia's tragic end: "May worms eat the innards of the person who is taking me away from my home. May his children not see his face in death."(Hanif 2008, p.93) and later, "May your blood turn to poison. May the worms eat your innards." (Hanif 2008, p.132) In the concluding chapter reader learns that it proves right. The curse has been fulfilled. His children didn't see his face as he was burnt in that plane crash; rather his blood turned to poison and the worms ate his innards in result of getting knocked by Ali Shigri's poisoned sword tip. And even if reader concludes this way that this is the reality, it still has makes some sense. This is the practical example of the assertion that culture, just like history and sign, is too a complement of meaning. Even the presence of the crow can also lead to a different interpretation that the crow who hit C130 was the same crow to whom Zainab used to feed and who came to avenge Zainabs's imprisonment.

\section{Conclusion}

In the light of above discussion, it is concluded that meaning is a product of play between the privileged (anything that is present, e.g., text), and the marginal (anything that is absent i-e thought, historical and cultural knowledge etc); and it is the marginal pole that completes and complements the privileged. As in In the Case of Exploding Mangoes, numerous characters and situations seem to be the root cause for the death of Gen Zia; and due to cultural and historical knowledge of the reader every suspicion seems holding some truth value. Hence, Derrida's critique that one signified defers to multiple signifiersmutually related - till infinity, makes the meaning ambiguous and fluid; and proves correct in the context of the selected novel. However, the novel has shown, with reference to the chosen corpus, the 'transcendental signified' contributes in the multiplicity of the meaning by opening up multifarious aspects of reality. The study also finds that history and culture, like 
language also builds a nexus that ultimately constructs the reality around us and gives meaning to the language and discourse surrounding us; and suggests that in order to deconstruct and demystify a particular discourse or text one needs to deconstruct all these structures.

\section{References}

Al-Muttalibi, A.Y. (2018). A deconstructive reading of Dickinson's poetic texts. Advances in Language and Literary Studies, 9(6), 144-147.

Derrida, J. (1972). Dissemination (Barbara Johnson, Trans.). Illinois, Chicago: University of Chicago Press. (Original work published 1969)

Derrida, J. (1978). Writing and Difference (Alan Bass, Trans.). Illinois, Chicago: University of Chicago Press. (Original work published 1967)

Derrida, J. (1982). Margins of Philosophy (Alan Bass, Trans.). Illinois, Chicago: University of Chicago Press. (Original work published 1972)

Derrida, J. (1997). Of Grammatology (G.C Spivak, Trans.). Baltimore, Maryland: The Johns Hopkins University Press. (Original work published 1967)

Hanif, M. (2008). A Case of Exploding Mangoes. New York, NY: Knopf Publishing House.

Maarof, M., et al. (2012). Young women speak out: Healing the selves through narrative therapy. GEMA Online® Journal of Language Studies, 12(2), 393-405.

Mambrol, N. (2016, March 22). Derrida's concept of differance. Literary Theory and Criticism. Retrieved from https://literariness.org/2016/03/22/derridas-concept-of-difference/

Miller, J.S. (1993). The Critic as Host: Deconstruction and Criticism. New York, NY: The Continum Publishing Company.

Pulido, D.H. (2011). Saving the Savior: A Deconstruction of the Novel Viajero by F. Sionil Jose. 3L: The Southeast Asian Journal of English Language Studies, 17(1), 79-92.

Richter, D. H. (Ed.). (1989). The Critical Tradition: Classic Texts and Contemporary Trends. Boston: NY, Bedford/St. Martin's.

Selden, R. (1989). A Reader's Guide to Contemporary Literary Theory. London: Harvester Wheatsheaf Publishers. 